\title{
Comparative Study between Open Fistulectomy and Ligation of Intersphincteric Fistulas Tract (LIFT) Procedure for Uncomplicated Perianal Fistula
}

\author{
${ }^{1}$ Dr. Mir Rasekh Alam Ovi, \\ MBBS, FCPS (Surgery), FMAS, \\ Consultant Surgery, General Hospital Narayangonj.
}

${ }^{3}$ Dr. Md. Musab Khalil, MRCP(UK), MD (Gastroenterology), Assistant Registrar, Sheikh Russel National Gastroliver Institue and Hospital, Mohakhali, Dhaka

\section{Abstract}

\section{$>$ Introduction:}

A new sphincter-saving procedure involving the ligation of the intersphincteric fistula tract (LIFT) procedure was recently described by Rojanasakul et al from Thailand. The main concept in the LIFT is to identify the fistula tract in the intersphincteric space and the subsequent ligation and division of the tract. Some studies abroad have shown a considerably high success rate in terms of wound healing and absence of incontinence in treating fistula-in-ano by this procedure. This study aimed to compare between the earlier fistulectomy and this new innovative LIFT technique.

\section{$>$ Methods:}

The study was designed as a comparative type of observational study conducted at Dhaka Medical College Hospital, Dhaka and Popular Medical College Hospital from January 2014 to December 2014. Study was carried out on 40 hospital admitted patients with uncomplicated Fistula-in-ano, irrespective of age and sex. LIFT and fistulectomy was the procedure as operative treatment for their disease. Outpatient follow-up was undertaken.

\section{$>$ Result:}

In our study, $30(\mathbf{7 5 \%})$ male and $10(25 \%)$ female patients were operated with a male to female ratio 3: 1 . Mean age was 37.3 years. Vast majority of the cases i.e 23 fistula $(68 \%)$ was inter-sphincteric type and the rest 17 (32\%) were trans-sphincteric type. Fistulectomy took less time than LIFT. Spinal Headache was the most common complication $7.5 \%$ ( 3 cases). No difference was found in comparison to wound healing. $(p=00.18)$. LIFT was found better than fistulectomy regarding post-operative incontinence ( $p=0.008$ ). LIFT was found better in term of recurrence $(p=0.04)$ than fistulectomy but in long term there is no difference $(p=0.3)$.

\author{
${ }^{2}$ Dr. Shamima Nasrin, \\ MBBS, FCPS (Surgery), FMAS, \\ Assistant Professor, Surgery, \\ Ad-din Women's Medical College \& Hospital \\ ${ }^{4}$ Dr. Farhan Imtiaz Chowdhury, \\ MBBS, FCPS (Surgery), Registrar Surgery, \\ Rajshahi Medical College Hospital
}

\section{> Conclusion: \\ In treatment of uncomplicated perianal fistula LIFT has no benefit over fistulectomy.}

\section{INTRODUCTION}

Fistula-in-ano is a difficult problem that physicians have struggled with since the time of Hippocrates. ${ }^{1}$ A thorough understanding of the relevant anatomy is essential in the management of fistula-in-ano. Anal fistula is a common complication after abscess formation, with cryptoglandular infection being the most widely accepted etiologic factor. ${ }^{2}$

Acharya Sushruta an ancient Indian Surgeon has described in his text ' Sushruta Samhita' about an ancient Ayurvedic technique of medicated thread called Ksharsutra treatment for Bhagandara ( Fistula in ano). Treatment of anal Fistula (Bhagandara)and Nadi-Vrana(Sinus) with Ksharsutra was practiced by Sushruta (1000-600B.C.). Hippocrates, in about $430 \mathrm{BCE}$, made reference to surgical therapy for fistulous disease and he was the first person to advocate the use of a seton (from the Latin seta, a bristle).

In 1376, the English surgeon John Arderne (13071390) wrote 'Treatises of Fistula in Ano; Haemmorhoids, and Clysters', in 1339, which described fistulotomy and seton use and recounted systematically the steps of the operation. It was he who first took recourse to the knife and believed laying the tract open with a director and a bistury. In the 14th Century, the surgical treatment for fistula was popularized as fashion of the day in France after the successful treatment of fistula-in-ano of King Luis XIV by surgeon Charles Felix, who was a barber surgeon to the court of the king and received a huge sum from him as a reward for operation. This made operative treatment the treatment of choice and 14th century was regarded as the golden age of rectal surgery. 
Later in the 18th century, percival Pott in his book on fistula-in-ano emphasized the need for exposing the fistulous tract by incision as mentioned by Arderne. Still later, for some time, the operative treatment was replaced by ligaturing the fistulous tract with strong silk or with India rubber ligatures. In the later part of the last century and also in the early part of this century, fistula was treated by the injections of irritant chemicals into the tract such as $3-4 \%$ silver nitrate, bismuth paste and a combination of quinine and urethane. Salmon established a hospital in London (St. Mark's) devoted to the treatment of fistula-inano and other rectal conditions None of these procedures were satisfactory and could not stand the test of the time, \& Fredrick Salmon soon came with his modicafication of the classical incision of fistulae, claiming better results.

In the late 19th and early 20th centuries, prominent physician/surgeons, such as Goodsall and Miles, Milligan and Morgan, Thompson, and Lockhart-Mummery, at the St. Mark's Hospital made substantial contributions to the treatment of anal fistula. These physicians offered theories on pathogenesis and classification systems for fistula-inano.

Since this early progress, little has changed in the understanding of the disease process. In 1976, Parks refined the classification system that is still in widespread use. Over the last 30 years, many authors have presented new techniques and case series in an effort to minimize recurrence rates and incontinence complications, but despite 2,000 years of experience, fistula-in-ano remains a perplexing surgical disease. ${ }^{3-6}$

The ideal treatment of fistula is based on 3 central tenets: (1) Control of sepsis; (2) closure of the fistula; and (3) maintenance of continence. ${ }^{1}$ Fistula surgery is a balance between recurrence and faecal continence disturbance. ${ }^{14}$ The aim of surgical treatment for anal fistula is to heal the fistula, possibly avoiding damage to the sphincter muscles. Various procedures have been developed to achieve this goal. The most common procedures include fistulotomy, fistulectomy, the use of Setons, the use of fistula plugs, the use of fistula glue, the use of flaps, the use of radiofrequency, the use of stem cells, and ligation of the intersphincteric fistula tract (LIFT). ${ }^{15}$

LIFT procedure was developed by Thai colorectal surgeon, Arun Rojanasakul, Colorectal Division Department of Surgery, Chulalongkorn University in Bangkok, Thailand. The first report of preliminary healing result from the procedure were $94 \%$ in $2007^{16}$ In 1993 Matos et al. described a technique of total anal sphincter preservation in high fistula in ano, which is based on the concept of excision of intersphincteric anal gland infection through the intersphincteric approach. ${ }^{17}$ This novel technique was also documented in Corman's textbook of colon and rectal surgery. ${ }^{18}$ However, the technique was not widely adopted. ${ }^{19}$ Between 2004 and 2005 there was a personal experience in the similar technique by group of surgeons. That technique included coring out the intersphinteric fistula tract from the external opening to the external sphincter, excision of the intersphincteric fistula tract and suture of the internal sphincter defect through the intersphincteric plane. The outcome in 20 patients was disappointing with only $9(45 \%)$ successes. Surgeons proposed that the reasons for the unfavorable outcome include dissection in the intersphincteric plane damaging blood supply to the internal opening area, and suturing delicate ischemic areas with increased risk of suture breakdown. Surgeons thought that ligation of the intersphincteric tract close to the internal opening might solve the problem. Surgeons noticed that during intersphincteric plane dissection if the internal sphincter was damaged and the anal mucosa breached, failure was common despite meticulous repair. ${ }^{17}$ Researchers of the procedure agree that the LIFT technique may cause some injury to internal sphincter, but theoretically LIFT causes less trauma of the internal sphincter than the other fistula operations. Matos et al. reported the technique of excision of the whole fistula tract plus primary repair, with intersphincteric plane approach for excision of the fistula tract and suturing of the internal anal sphincter defect, in 1993. ${ }^{18}$ However, Rojanasakul reported the ligation of intersphincteric fistula tract in 2007 with apparent satisfactory results probably due to secured closure of the internal opening. ${ }^{17}$ This represents a significant change from the originally described technique with improved outcomes. ${ }^{14}$

Fistula-in-ano is a difficult problem that physicians have struggled with for centuries. LIFT is comparatively new procedure then conventional Fistulectomy in management of fistula in ano. Risk of incontinence is the main challenge of surgery. The aim of this study is to find out the initial outcome of LIFT compared to fistulectomy in terms of healing and incidence of incontinence.

\section{METHODOLOGY}

This was a comparative study. The study was conducted over a period of four years (i.e. $1^{\text {st }}$ January 2014 to $31^{\text {st }}$ December 2017) in the Department of Surgery of $\mathrm{DMCH}$ and different private medical college hospitals. Within the period, 40 patients were prospectively selected for the study. 20 patients underwent LIFT and 20 under open fistulectomy.

Detail history was taken (history of IBD, previous malignancy, previous anal operation other than fistula, incontinence etc.) Clinical examination was done methodically. Proper documentation of clinical examination and DRE findings were done. Pre-operative evaluation for fitness for surgery is evaluated both clinically and by lab investigations. Fistulogram was done.

Patients who refused to give consent to be included in this study, fistula secondary to IBD, with preexisting incontinence, with past or present malignancies, patient with trauma, who need for additional concomitant anorectal surgery, with inadequate information were excluded.

Structured questionnaire and data sheet were used to collect data. 
In this study uncomplicated fistula means, fistula not due to secondary cause like IBD, Malignancy, Actinomycosis etc. Open fistulectomy means excision of the fistulas tract and lay open for secondary healing. And LIFT means to identify the fistula tract in the intersphincteric space and then subsequently ligate it. A portion of the fistula tract can also be excised at the time of division and ligation.

Patients were admitted 1 day before or on the day of surgery. Per operative single dose IV antibiotic was used (ceftriaxone and metronidazole). All of the patients were discharged in the following day with analgesia, oral antibiotic and stool softeners. Full examination was done before operation.

In open fistulectomy patients were operated under spinal anesthesia in lithotomy position. Injection of hydrogen peroxide / methylene blue was done to identify the internal opening then a grooved fistula probe was inserted from the external opening to identify the internal opening. Fistulectomy was performed. The whole fistula tract was excised around the probe by electric cautery dissection. Hemostasis was secured by pressure or diathermy and the wound was lightly packed.

Ligation of Intersphincteric Fistula Tract (LIFT) was done under general anesthesia in prone-Jackknife position. An internal opening was identified by injecting methylene blue or hydrogen peroxide from an external opening, and an incision was made parallel to the anal verge. Dissection deep down into intersphincteric space was carried out with electric cautery to identify the fistula tract. This tract was then ligated on the internal opening site by vicryl $3 / 0$ before being transected. In order to confirm that it was the correct tract, methylene blue or hydrogen peroxide was injected, after which the tract was ligated on the external site with vicryl $3 / 0$. The wound was lightly packed.

Patient visits were scheduled at 4,8 and 12 weeks after surgery. A last follow up was done afet one year of surgery. Healing of the fistula was defined as complete wound healing and closure of all external openings in combination with the absence of symptoms. Further followup information was obtained from both a questionnaire and telephone communication. Faecal continence was evaluated by the below mentioned clinical continence grading. ${ }^{20}$

Category A: continent of solid and liquid stools and flatus (i.e. normal continence)

Category B: continent of solid and usually liquid stools but not flatus (no fecal leakage)

Category C: acceptable continence for solid stool but no control over liquid stool or flatus (intermittent fecal leakage)

Category D: continued fecal leakage

This was assessed before and at 12 weeks after the procedure. Pre- and post-operative digital examination was performed to assess the integrity of the anal sphincter muscles.

Assessment of wound healing was done by the following grading. ${ }^{20}$

Grade 1: complete epithelialization of the wound

Grade 2: healing wound with granulation

Grade 3: granulation with purulent discharge

Grade 4, non-healing: the wound did not heal at ten weeks or re-operation was needed

\section{RESULT}

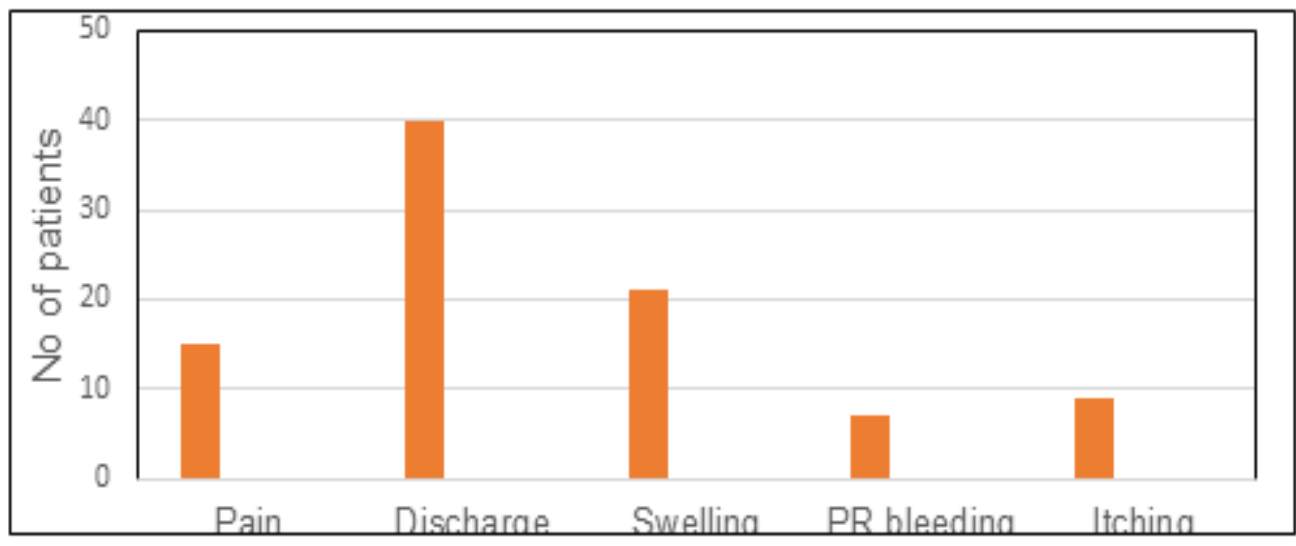

Fig 1:- Presenting symptoms

All the patients presented with intermittent discharge $(100 \%, \mathrm{n}=40)$. The second most complaints was swelling (21 patients, $52 \%$ ) 


\begin{tabular}{|c|c|c|}
\hline Characteristics & Fistulectomy, n=20 & LIFT, n=20 \\
\hline Age, $y$ & $\begin{array}{c}\text { Mean }=37.3 \\
\text { Mode }=30(3 \mathrm{pt})\end{array}$ & $\begin{array}{c}\text { Mean }=32.5 \\
\text { Mode }=36(2 \mathrm{pt})\end{array}$ \\
\hline Sex (Male : Female) & $13: 7$ & $17: 3$ \\
\hline Socio economic condition & $1(5 \%)$ & $1(5 \%)$ \\
\hline Rich & $2(10 \%)$ & $3(15 \%)$ \\
\hline High middle class & $4(20 \%)$ & $9(45 \%)$ \\
\hline Middle class & $3(15 \%)$ & $5(25 \%)$ \\
\hline Pow middle class & $10(50 \%)$ & $2(10 \%)$ \\
\hline
\end{tabular}

Table 1:- Characteristics of participants

Table 1 shows the characteristics of the patients. Mean age of the fistulectomy and LIFT patients were 37.3 years and 32.5 years respectably. There were male predominance in both the group. $10(50 \%)$ patients were poor who underwent fistulectomy where it is $9(45 \%)$ from the middle class in LIFT.

\begin{tabular}{|c|c|c|}
\hline Distance from anal verge & Fistulectomy, $\mathbf{n = 2 0}$ & LIFT, n=20 \\
\hline$<1 \mathrm{~cm}$ & $1(5 \%)$ & 0 \\
\hline $1-2 \mathrm{~cm}$ & $8(40 \%)$ & $3(15 \%)$ \\
\hline $2-3 \mathrm{~cm}$ & $5(20 \%)$ & $14(70 \%)$ \\
\hline $3-4 \mathrm{~cm}$ & $5(20 \%)$ & $3(15 \%)$ \\
\hline$>4 \mathrm{~cm}$ & $1(5 \%)$ & 0 \\
\hline
\end{tabular}

Table 2 Situation of external opening

$14(70 \%)$ patients of the LIFT group had the position of the external opening in between $2-3 \mathrm{~cm}$.

\begin{tabular}{|c|c|c|c|}
\hline & Fistulectomy, n=20 & LIFT, n=20 & Total, n=40 \\
\hline Fistula type & $7(35 \%)$ & $16(80 \%)$ & $23(68 \%)$ \\
\hline Trans sphincteric & $13(65 \%)$ & $4(20 \%)$ & $17(32 \%)$ \\
\hline Supra sphincteric & 0 & 0 & 0 \\
\hline Extra sphincteric & 0 & 0 & 0 \\
\hline
\end{tabular}

Table 3:- Type of fistula

$3(65 \%)$ patients had Transsphincteric fistula who underwent fistulectomy. On the other hand 16 (80\%) patients had Intersphincteric fistula in the LIFT group.

\begin{tabular}{|c|c|c|}
\hline Time range (minute) & Fistulectomy, n=20 & LIFT, n=20 \\
\hline $0-30$ & $16(80 \%)$ & 0 \\
\hline $30-60$ & $3(15 \%)$ & $1(5 \%)$ \\
\hline $60-90$ & $1(5 \%)$ & $17(85 \%)$ \\
\hline $90-120$ & 0 & $2(10 \%)$ \\
\hline
\end{tabular}

Table 4:- Time taken for operation

Fistulectomy took less time than LIFT. $16(80 \%)$ patients were operated within 0-30 min by fistulectomy. In LIFT 17 (85\%) patients were operated within 60-90 min.

\begin{tabular}{|c|c|c|c|}
\hline Diagnosis & Fistulectomy, $\mathbf{n = 2 0}$ & LIFT, $\mathbf{n = 2 0}$ & Total ,n=40 \\
\hline Hemorrhage & 2 & 0 & $2(5 \%)$ \\
\hline Spinal Headache & 1 & 2 & $3(7.5 \%)$ \\
\hline Fever & 2 & 0 & $2(5 \%)$ \\
\hline Pain at puncture site & 1 & 1 & $2(5 \%)$ \\
\hline Urinary retention & 1 & 1 & $2(5 \%)$ \\
\hline Total & 7 & 4 & $11(27 \%)$ \\
\hline
\end{tabular}

Table 5:- Post-operative complication 
Spinal Headache was the most common complication. 7.5\% (3 cases) was affected where 1 from the fistulectomy group and 2 from the LIFT group.

\begin{tabular}{|c|c|c|c|}
\hline Grade & Fistulectomy, n=20 & LIFT, n=20 & Total, n=40 \\
\hline Grade 1 & $15(75 \%)$ & $19(95 \%)$ & $34(85 \%)$ \\
\hline $\begin{array}{c}\text { Grade 2,Grade 3 and } \\
\text { Grade 4 }\end{array}$ & $5(15 \%)$ & $1(5 \%)$ & $6(15 \%)$ \\
\hline Total & 20 & 20 & $40(100 \%)$ \\
\hline
\end{tabular}

$\mathrm{P}$ value $0.18(>0.05)$

Table 6:- Status of wound healing

95\% (19 cases) of LIFT patients had excellent wound healing while it is 75\% (15 cases) in fistulectomy group.

\begin{tabular}{|c|c|c|c|}
\hline Continence & Fistulectomy & LIFT & Total \\
\hline $\begin{array}{c}\text { Category A } \\
\text { (normal ) }\end{array}$ & 13 & 20 & 33 \\
\hline Category B, C and D & 7 & 0 & 7 \\
\hline Total & 20 & 20 & 40 \\
\hline
\end{tabular}

$\mathrm{P}$ value $0.008(<.05)$

Table 7:- Post-operative clinical continence grading found.

LIFT was found better than fistulectomy in terms of incontinence $(p=.008)$. Although Category D continence was not

\begin{tabular}{|c|c|c|}
\hline Discharged on & Fistulectomy & LIFT \\
\hline $1^{\text {st }}$ POD & 3 & 9 \\
\hline $2^{\text {nd }}$ POD & 2 & 6 \\
\hline $3^{\text {rd }}$ POD & 15 & 4 \\
\hline $4^{\text {th }}$ POD & 0 & 1 \\
\hline$>4^{\text {th }}$ POD & 0 & 0 \\
\hline
\end{tabular}

POD $=$ post-operative day

Table 8:- Post-operative hospital stay

In the study $15(75 \%)$ patients were discharged in the $3^{\text {rd }}$ POD in the fistulectomy group. In the LIFT group $9(45 \%)$ patients were discharged on the $1^{\text {st }}$ POD.

\begin{tabular}{|c|c|c|c|}
\hline Duration & Fistulectomy & LIFT & P value \\
\hline $1-4$ weeks & 0 & 0 & \multirow{2}{*}{$0.04(<.05)$} \\
\hline $5-8$ weeks & 2 & 1 & $0.3(>.05)$ \\
\hline $9-12$ weeks & 4 & 2 & \\
\hline$>12$ weeks & 0 & 3 & \\
\hline Total & 6 & & \\
\hline
\end{tabular}

Table 9:- Recurrence, $\mathrm{n}=40$

Total 9 (40\%); $\mathrm{n}=40$, patients had recurrence. Among them 6 had fistulectomy and 3 had LIFT.

\section{DISCUSSION}

General objective in the present study was to compare between fistulectomy and ligation of intersphincteric fistula tract (LIFT) procedures. Outcome of these procedures were assessed in different terms. In our study, among 40 patients, $30(75 \%)$ male and rest female patients were operated with a male to female ratio 3: 1 . Dominancy of male patient were observed in other two literature, although one of the study could maintain an almost 50: 50 ratio. ${ }^{21-23}$ This does not indicate a male predominance of fistula-in-ano among society as the study population was too small and it was a purposive sampling. The mean age (37.3) was almost similar of other studies mentioned above. Among the LIFT 
group $9(45 \%)$ patients are of middle class and in the fistulectomy group $10(50 \%)$ patients are from poor socioeconomic group. It does not indicate the predominance of fistula in ano in these group as because most of the fistulectomy patients were from government hospital and LIFT patients were from private setting.

All the patients presented with intermittent discharge $(100 \%, \mathrm{n}=40)$. The second most complaints was swelling (21 patients, $52 \%$ ). Different studies support this findings. ${ }^{12}$ During EUA, distance of external opening from the anal verge was measured. Majority of the cases i.e in 14 cases (70\%) external opening of the fistula tract in the was found within $2-3 \mathrm{~cm}$ from the anal verge in the LIFT group and in the fistulectomy group $9(45 \%)$ patients it was within 1-2 $\mathrm{cm}$. During the procedure, $13(65 \%)$ patients had Transsphincteric fistula who underwent fistulectomy. On the other hand $16(80 \%)$ patients had Intersphincteric fistula in the LIFT group.

Fistulectomy took less time than LIFT. 16 (80\%) patients were operated within 0-30 $\mathrm{min}$ in fistulectomy group. In LIFT most of the operations could be completed within 30-60 minutes with comprised $85 \%$ (17 cases). Only one journal exposed the operation time and they were a little bit faster than this study. ${ }^{22}$ Though the time is not a factor against a successful outcome, it gives an idea about the relative easiness of the procedure.

Degree of postoperative pain is a major determinant of patient satisfaction. We encouraged warm Sitz bath from first post-operative day to all patients but it could not spare the need for an analgesic. Sitz bath was allowed to reduce postoperative pain due to its soothing effect as well as to keep perianal area less contaminated. Original author used tap water to clean perianal area. ${ }^{16}$

Spinal Headache was the most common complication. $7.5 \%$ ( 3 cases) was affected where 1 from the fistulectomy group and 2 from the LIFT group

95\% (19 cases) of LIFT patients had excellent wound healing while it is $75 \%$ (15 cases) in fistulectomy group. No difference was found in comparison to wound healing. $(\mathrm{p}=0.18)$

In this study no anal incontinence was observed among the patients undergone LIFT procedure. Incidence of anal incontinence was excluded by asking the patient for any leak of flatus, liquid or formed stool. While 7 (35\%) patients had abnormal continence. LIFT was found better than fistulectomy in terms of incontinence $(\mathrm{p}=.008)$. Although Category D continence was not found. Similar findings regarding continence was found in one study $(\mathrm{p}=.035)^{24}$

In the study $15(75 \%)$ patients were discharged in the $3^{\text {rd }}$ POD in the fistulectomy group. In the LIFT group 9 (45\%) patients were discharged on the $1^{\text {st }}$ POD In few centers LIFT procedure was done on an outpatient basis ${ }^{21}$ but in our set up, as it was a new procedure to us, to have better control and follow up of the patient we performed the procedure as admitted cases. GOVT setup needed more time before operation than the private setup.

Total 8 (40\%); $n=40$, patients had recurrence. Among them 7 had fistulectomy and 1 had LIFT. LIFT was found safe in term of recurrence $(\mathrm{p}=.04)$ than fistulectomy. One study found similar recurrence rate in LIFT procedure. ${ }^{24}$

\section{LIMITATIONS}

This study lacks some strengthening factors. One is the sample size which could be a bigger one in other set up except a prerequisite for fellowship training. Sampling technique was purposive sampling. A non-purposive one with a bigger sample size could also be helpful to determine the types and nature of fistula in our country.

Our study is a prospective study which lacked adequate power to determine differences in patient preoperative variables such as seton or bowel preparation. True comparison and advantage of the LIFT procedure may not be clear until larger prospective, randomized studies are performed.

Only patients with uncomplicated fistula tract were in the study. With experience and success of LIFT procedure an attempt may later be taken into consideration to include complicated fistula in further study. Moreover Fistulectomy is an old procedure in comparison to LIFT.

\section{RECOMMENDATIONS}

True comparison and advantage of the LIFT procedure may not be clear until larger prospective, randomized studies are performed. It could be compared with newer techniques like seton application, fistula plug or anal advancement flap to say the LIFT procedure as an alternative to the previously well-established sphincter saving procedures. Randomized controlled trials with longterm follow-up are necessary to include LIFT as a standard treatment option for fistula-in-ano. Transrectal USG or MRI fistulogram could be an useful diagnostic tool to detect type of fistula. But these were avoided to reduce unnecessary treatment cost. These investigating tools on further study may be considered later regarding the effectiveness of LIFT procedure in different variety of fistula.

\section{CONCLUSION}

With the current reported data in consideration, we believe that the Ligation of Intersphincteric Fistula Tract (LIFT) procedure is a safe and more economical technique with minimal tissue injury and low recurrence rates. This new technique for fistula-in-ano surgery aimed at total anal sphincter preservation has shown encouraging early results. The technique is promising and has potential to be a valid option for the treatment of fistula-in-ano. Attention to details of the technique is the key to success. This procedure is relatively easy to perform and appears to be 
safe yet In treatment of uncomplicated perianal fistula LIFT has no benefit over fistulectomy.

\section{REFERENCES}

[1]. Sainio P. Fistula-in-ano in a defined population. Incidence and epidemiological aspects. Ann Chir Gynaecol 1984; 73: 219-24.

[2]. Wexner SD, Shawki S. Idiopathic fistula-in-ano. World J Gastroenterol 2011; 17:3277-85.

[3]. http://en.wikipedia.org/wiki/Anal_fistula

[4]. http://emedicine.medscape.com/article/190234overview

[5]. http://en.wikipedia.org/wiki/Kshara

[6]. http://www.way2ayurveda.com/fistulainano

[7]. Williams NS, Bulstrode CJK, O'connell PR. The anus and anal canal. Baily \& Love's Short Practice of Surgery. New York: CRC press, 2013;73:1259-63

[8]. Steele SR, Kumar R, Feingold DL et al. Practice parameters for the management of perianal abscess and fistula-in-ano. Dis Colon Rectum 2011; 54:146574.

[9]. Julie A, Rizzo MD, Anna L, Naig MD. Anorectal Abscess and Fistula-in-Ano: Evidence-Based Management. Surg Clin N Am. 2010; 90(1):45-68.

[10]. Sandborn WJ, Fazio VW, Feagan BG, Hanauer SB. AGA technical review on perianal Crohn's disease. Gastroenterology. 2011; 125:1508-30.

[11]. Parks AG, Gordon PH, Hardcastle JD. A classification of fistula-in-ano. Br J Surg 1976; 63:1-12.

[12]. Vasilevsky CA, Beck DE, Roberts PL et al. Anorectal abscess and fistula. The AS-CRS Text book of colon and rectal surgery. Springer, New York, 2011, 219-44.

[13]. Bleier J, Moloo H. Current management of cryptoglandular fistula-in-ano. World J Gastroenterol. 2011; 17:3286-91.

[14]. Rojanasakul A. LIFT procedure a simplified technique for fistula-in-ano. Tech Coloproctol.2011; 13:237-40.

[15]. Garcia-Aguilar J, Belmonte C, Wang WD, Goldberg SM, Madoff RD. Anal fistula surgery. Factors associated with recurrence and incontinence. Dis Colon Rectum 1996; 39:723-29.

[16]. Rojanasakul A, Pattanaarun J, Sahakitrungruang C, Tantiphlachiva K. Total anal sphincter saving technique for fistula-in-ano; the ligation of intersphincteric fistula tract. J Med Assoc Thai. 2007 ;90(3):581-6.

[17]. Matos D, Lunniss PJ, Phillips RKS. Total sphincter conservation in high fistula in ano: results of a new approach. Br J Surg.1993; 80:802-4.

[18]. Corman M L. Anal Fistula. In: Colon and Rectal Surgery. Lippincott Williams \& Wilkins.2004, 316.

[19]. Lunnis PJ. Invited comment: LIFT procedure: a simplified technique for fistula in ano. Tech Coloproctol.2009; 13:241-42.

[20]. Browning GG, Parks AG. Postanal repair for neuropathic faecal incontinence: correlation of clinical result and anal canal pressures. Br J Surg. 1983; 70: 101-4.
[21]. Armen A, Amy HK, Ravin RK. Early result of ligation of the intersphincteric fistula tract for fistulain-ano. Dis Colon Rectum. 2011; 54: 289-292.

[22]. Shanwani A, Nor AM, Amri N. Ligation of the Intersphincteric Fistula Tract (LIFT): a SphincterSaving Technique for Fistula-in-Ano. Dis Colon Rectum. 2010; 53: 39-43

[23]. Joshua ISB, Husein M, Stanley MG. Ligation of the Intersphincteric Fistula Tract: An Effective New Technique for Complex Fistulas. Dis Colon Rectum. 2010; 53: 43-46

[24]. Chrispen M, Lynne B,Bettina S, Yik HH. Ligation of intersphincteric fistula tract compared with advancement flap for complex anorectal fistulas requiring initial seton drainage. The American Journal of Surgery .2012; 204, 283-89.

[25]. Zuhair BK. Fistulotomy Versus Fistulectomy As a Primary Treatment of Low Fistula in Ano. The Iraqi postgraduate medical journal. 2012; 11(4), 1-10. 